\title{
Observations on cardiovascular and neuroendocrine disturbance in the Guillain-Barré syndrome
}

\author{
A. G. DAVIES AND H. R. DINGLE \\ From the Assisted Respiration Unit, Llandough Hospital, Penarth, Glam.
}

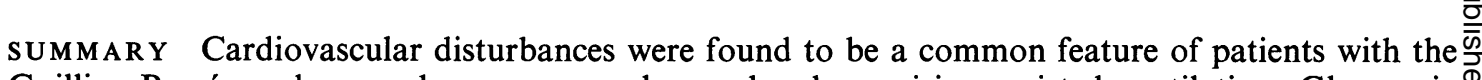
Guillian-Barré syndrome who were severely paralysed, requiring assisted ventilation. Glycosuria $\varnothing$ was noted in association with these disturbances, and in five patients investigated we found impaired $ळ$ glucose tolerance tests at the height of the paralysis. Catecholamine and 17-hydroxycorticosteroid $\vec{\circ}$ urinary excretions were found to be high in four patients investigated when the neuropathy was most $\overrightarrow{-}$ severe, and in one patient plasma cortisol levels were high with loss of diurnal variation. With $\vec{\omega}$ recovery from paralysis cardiovascular disturbances became less marked, catecholamine and $\widehat{\bar{J}}$ 17-hydroxycorticosteroid urinary excretions reverted to normal, glucose tolerance improved but remained abnormal in three patients during the period of observation. It is suggested that increased $\omega_{\mathrm{G}}$ levels of catecholamines and cortisol contributed to the development of impaired glucose tolerance i and cardiovascular disturbances.

Since the advent of assisted respiration for the treatment of respiratory failure in the GuillainBarré syndrome the mortality of this disease has been reduced from between $30 \%$ and $50 \%$ to less than 10\% (Miller, 1966). Cardiovascular disturbances are now a significant factor in mortality. We observed an association between cardiovascular disturbance and the presence of glycosuria in the Guillain-Barré syndrome. We report here the results of glucose tolerance tests, catecholamine, and 17-hydroxycorticosteroid urinary excretion in some of our patients.

\section{METHODS}

Five patients with the Guillain-Barré syndrome were investigated (see Table). All had an acute symmetrical polyneuritis in which motor involvement predominated over sensory changes; the cerebrospinal fluid protein was high with a normal cell count, except in patient no. 1 whose clinical course was complicated by a subarachnoid haemorrhage. Poliomyelitis and porphyria were excluded by the appropriate tests. All patients developed respiratory failure which necessitated tracheostomy and intermittent positive pressure ventilation (IPPR). They were nursed lying flat and turned two-hourly from side to side. A Complan diet containing 2,500 calories and approximately $400 \mathrm{~g}$ of carbohydrate was given by a nasogastric tube.

Blood pressure and pulse rate were recorded half hourly by the nursing staff. Capillary blood glucose concentrations were measured by a modification off the glucose oxidase method (Clark and Timms, 1968) two hours after a $50 \mathrm{~g}$ glucose meal followi g an overnight fast. Urinary 24-hour 3 methox $\bar{x}-0$ hydroxymandelic acid (VMA) excretions were? estimated using the method of Georges and Small (1962). The upper limit for this laboratory is $8 \mathrm{mg} / 24$ hours. Analysis of 24-hour urinary excretion of $\frac{\partial}{0}$ 17-hydroxycorticosteroids (17-OHCS) was made using the method of Few (1961). Plasma 11-hydroxy- $\stackrel{\odot}{\propto}$ corticosteroids (11-OHCS) were estimated according $\overrightarrow{\vec{\partial}}$ to Mattingley's method (1962).

\section{RESULTS}

In all five patients cardiovascular disturbances became apparent as paralysis progressed. All $:$ patients developed a pulse rate of over 100 per 3 minute at the height of the neuropathy and blood $\delta$ pressure became extremely labile (see Table). Systolic and diastolic blood pressures were 은 greatly elevated on occasions; readings of $300 D$ $\mathrm{mmHg}$ systolic and $140 \mathrm{mmHg}$ diastolic were recorded. A hypertensive crisis was probably o responsible for the subarachnoid haemorrhage $N$ in patient no. 1. Sudden hypotension with blood N pressure readings of $50 \mathrm{mmHg}$ systolic occasion- $O$ ally alternated with hypertensive bouts. Electrocardiographic (ECG) changes occurred in all $\frac{0}{\varnothing}$ patients except patient no. 5. These consisted of $\stackrel{?}{?}$ $\mathrm{S}-\mathrm{T}$ segment flattening and $\mathrm{T}$-wave inversion $\mathrm{T}$ 
TABLE

CLINICAL FEATURES AND INVESTIGATIONS

\begin{tabular}{|c|c|c|c|c|c|c|c|c|c|c|}
\hline \multirow[b]{2}{*}{$\begin{array}{l}\text { ge of illness } \\
\text { lood pressure } \\
\text { lbility }(\mathrm{mmHg})\end{array}$} & \multicolumn{5}{|c|}{ Patient no. 1 (age 56, female) } & \multicolumn{5}{|c|}{ Patient no. 2 (age 16, male) } \\
\hline & 1 & 2 & 3 & 4 & 5 & 1 & 2 & 3 & 4 & 5 \\
\hline Systolic variation & - & $88 \pm 27$ & $74 \pm 38$ & $30 \pm 14$ & $31 \pm 16$ & $40 \pm 14$ & $40 \pm 13$ & $27 \pm 11$ & $24 \pm 10$ & $18 \pm 8$ \\
\hline $\begin{array}{l}\text { Diastolic variation } \\
\text { 1ge of } \mathrm{BP}(\mathrm{mmHg})\end{array}$ & - & $42 \pm 16$ & $42 \pm 20$ & $23 \pm 10$ & $17 \pm 8$ & $30 \pm 0$ & $31 \pm 9$ & $22 \pm 8$ & $18 \pm 9$ & $13 \pm 7$ \\
\hline Systolic & - & 110 to 250 & 50 to 300 & 120 to 180 & 100 to 160 & 100 to 160 & 100 to 190 & 110 to 170 & 100 to 150 & 110 to 140 \\
\hline Diastolic & - & 60 to 140 & 0 to 150 & 50 to 110 & 60 to 110 & 50 to 100 & 50 to 110 & 60 to 110 & 60 to 100 & 60 to 90 \\
\hline se rate $(/ \mathrm{min})$ & - & 70 to 160 & 80 to 120 & 60 to 100 & 60 to 100 & 80 to 130 & 75 to 135 & 80 to 130 & 70 to 100 & 75 to 100 \\
\hline$G$ changes & - & + & - & + & - & - & + & - & - & 0 \\
\hline $\begin{array}{l}\text { nary excretion of VMA } \\
\mathrm{mg} / 24 \mathrm{hr} \text { ) }\end{array}$ & & $\begin{array}{l}17 \cdot 5 \\
14 \cdot 1\end{array}$ & - & $2 \cdot 3$ & - & - & $12 \cdot 3$ & $3 \cdot 2$ & - & - \\
\hline $\begin{array}{l}\text { inary excretion of } \\
7-\mathrm{OHCS}(\mathrm{mg} / 24 \mathrm{hr}) \\
\text { lormal range }\end{array}$ & - & - & $\begin{array}{c}21 \cdot 9 \\
2 \cdot 5 \text { to } 11\end{array}$ & - & $8 \cdot 3$ & - & 54.9 & 3 to 14 & - & $8 \cdot 3$ \\
\hline urnal variation of plasma & - & - & - & - & - & - & - & - & - & - \\
\hline $\begin{array}{l}\text { 1-OHCS }(\mu \mathrm{g} / 100 \mathrm{ml} .) \\
\mathrm{r} \text { blood glucose }\end{array}$ & - & - & - & - & - & - & - & - & - & - \\
\hline $\mathrm{mg} / 100 \mathrm{ml})$. & - & 264 & - & 198 & 131 & - & 118 & 120 & - & 83 \\
\hline
\end{tabular}

ge of illness

ilood pressure

ability $(\mathrm{mmHg})$

Systolic variation

Diastolic variation

nge of $\mathrm{BP}(\mathrm{mmHg})$

Systolic

Diastolic

Ise rate $(/ \mathrm{min})$

G changes

inary excretion of VMA

$\mathrm{mg} / 24 \mathrm{hr}$ )

inary excretion of

7-OHCS (mg/24 hr)

Jormal range

urnal variation of plasma

11-OHCS $(\mu \mathrm{g} / 100 \mathrm{ml}$.)

ir blood glucose

$\mathrm{mg} / 100 \mathrm{ml}$.)
Patient no. 3 (age 63, female)

\begin{tabular}{|c|c|c|c|c|}
\hline 1 & 2 & 3 & 4 & 5 \\
\hline $\begin{array}{l}40+26 \\
30 \pm 17\end{array}$ & $\begin{array}{l}83 \pm 33 \\
51 \pm 14\end{array}$ & $\begin{array}{l}52 \pm 10 \\
32 \pm 8\end{array}$ & $\begin{array}{l}27 \pm 11 \\
25 \pm 7\end{array}$ & $\begin{array}{l}13 \pm 6 \\
13 \pm 6\end{array}$ \\
\hline $\begin{array}{l}140 \text { to } 200 \\
80 \text { to } 120 \\
85 \text { to } 120 \\
+\end{array}$ & $\begin{array}{l}70 \text { to } 220 \\
80 \text { to } 130 \\
80 \text { to } 130 \\
+\end{array}$ & $\begin{array}{l}80 \text { to } 170 \\
50 \text { to } 100 \\
75 \text { to } 125 \\
+\end{array}$ & $\begin{array}{l}90 \text { to } 160 \\
40 \text { to } 100 \\
75 \text { to } 120 \\
-\end{array}$ & $\begin{array}{c}110 \text { to } 130 \\
60 \text { to } 80 \\
75 \text { to } 95 \\
0\end{array}$ \\
\hline 6.4 & 10 & - & - & 4 \\
\hline $16 \cdot 3$ & - & 2 to $\overline{10} \cdot 3$ & $2 \cdot 7$ & - \\
\hline $\begin{array}{c}9 \text { a.m. } \\
36 \cdot 4 \\
11 \text { p.m. } \\
28 \cdot 2\end{array}$ & - & - & $\begin{array}{c}9 \text { a.m. } \\
22 \cdot 8 \\
11 \text { p.m. } \\
9 \cdot 5\end{array}$ & - \\
\hline
\end{tabular}

208
Patient no. 4 (age 72, male)

$\begin{array}{lllll}1 & 2 & 3 & 4 & 5\end{array}$

$\begin{array}{llll}31 \pm 12 & 60 \pm 16 & 70 \pm 18 & 62 \pm 2 \\ 24 \pm 14 & 31 \pm 9 & 44 \pm 12 & 45 \pm 15\end{array}$

130 to $190 \quad 70$ to $170 \quad 70$ to $180 \quad 70$ to $180 \quad 90$ to 170

70 to $130 \quad 50$ to $110 \quad 30$ to $110 \quad 30$ to $115 \quad 30$ to 115

80 to 10570 to $120 \quad 55$ to 13075 to $125 \quad 75$ to 110 बे

$+\quad+\quad+\quad 0 \quad$ N

$\begin{array}{lllll}6.6 & 17 \cdot 3 & 10 \cdot 2 & - & 4\end{array}$

$-\quad 15 \cdot 3$

4 to $14 \cdot 5$

$4 \cdot 1$

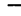

138

158

124

Patient no. 5 (age 55, male)

Ige of illness

3lood pressure

ability $(\mathrm{mmHg})$

Systolic variation

Diastolic variation

Inge of BP (mmHg)

Systolic

Diastolic

Ise rate $(/ \mathrm{min})$

¿G changes

inary excretion of VMA

(mg/24 hr)

inary excretion of

17-OHCS (mg/24 hr)

Vormal range

urnal variation of plasma

11-OHCS ( $\mu \mathrm{g} / 100 \mathrm{ml}$.)

ir blood glucose

$(\mathrm{mg} / 100 \mathrm{ml}$ )

$2 \quad 3 \quad 45$

$\begin{array}{lcccc}- & 26 \pm 9 & 27 \pm 12 & 25 \pm 6 & 11 \pm 5 \\ - & 24 \pm 5 & 33 \pm 6 & 23 \pm 13 & 13 \pm 6 \\ - & 110 \text { to } 150 & 110 \text { to } 150 & 100 \text { to } 140 & 100 \text { to } 130 \\ - & 60 \text { to } 90 & 60 \text { to } 100 & 50 \text { to } 90 & 60 \text { to } 80 \\ - & 75 \text { to } 115 & 70 \text { to } 115 & 65 \text { to } 105 & 60 \text { to } 85\end{array}$

KEY

Stages of illness

1. Onset of illness to tracheostomy and I.P.P.R.

2. Tracheostomy and I.P.P.R. to height of paralysis.

3. Height of paralysis to commencement of weaning off ventilator.

4. Weaning period.

5. Off ventilator.

* Blood pressure lability is represented by the mean $( \pm S D)$ daily range of systolic and diastolic blood pressures of each stage of illness.

+ Normal range corrected for age and sex.

+ Present.

Absent.

- Not done. 
affecting mainly leads II and III, AVF, and $\mathrm{V}_{1}$ to $V_{3}$ but occasionally seen in AVL and $V_{4}$ to $V_{6}$. Patient no. 4 developed ventricular extra systoles. Blood gas estimations in all patients ruled out anoxia, hypercapnia, and hypocapnia $\left(\mathrm{pCO}_{2}<30 \mathrm{mmHg}\right.$ ) as possible factors for these disturbances except in patient no. 4. Difficulty was experienced in weaning him off the ventilator because he suffered from chronic bronchitis and ankylosing spondylitis and occasionally became hypercapnic $\left(\mathrm{pCO}_{2}<59 \mathrm{mmHg}\right.$ ). This possibly contributed to the vasomotor instability seen in this stage of his illness. Patients nos. 1, 2, and 3 had retention of urine which was quickly recognized and required catheterization. This event did not appear to contribute to the cardiovascular disturbances. As the paralysis diminished the cardiovascular disturbances became less marked and the ECG reverted to normal in all except patient no. 1 (see Table).

Glycosuria was noted in patients nos. 1, 3, and 5 at the height of the illness. Impaired glucose tolerance developed in association with this as indicated by a high two hour blood glucose concentration (see Table). As the neuropathy abated, glucose tolerance improved and reverted to normal except in patients nos. 1, 3, and 4 . There was no family history of diabetes mellitus in any of these patients. VMA estimations in four patients revealed a higher than normal urinary excretion at the height of the illness when cardiovascular disturbance was severe. With recovery from paralysis VMA excretion returned to within normal limits (see Table). The urinary excretion of 17-OHCS followed a similar pattern (see Table). Plasma 11-OHCS concentrations were measured in patient no. 3 and were high, with loss of diurnal variation during deterioration of the neuropathy. Plasma concentrations returned to normal and diurnal variation was re-established when the neuropathy improved.

\section{DISCUSSION}

Hypertension and tachycardia contributed to the death of 11 of 50 fatal cases of Guillain-Barré syndrome examined by Haymaker and Kernohan (1949). An abnormally labile blood pressure was also noted by Marshall (1963) and Eiben and Gersony (1963); the latter regarded this as a poor prognostic sign. One of our patients, not included in the present series, died after a hypotensive episode and patient no. 1 developed a sub- arachnoid haemorrhage, probably as a result of a hypertensive crisis. Cardiovascular disturbances characteristically occur only in severely paralysed cases at the height of the illness. Apart from patient no. 4, these disturbances could not be attributed to poor ventilation. Marshall (1963) also noted that these disturbances occurred in well ventilated patients.

It has been suggested that these disturbances are due to autonomic nervous system involvement. Appenzeller and Marshall (1963) suggested a central lesion but Spalding and Smith (1963) postulated an interruption of the autonomic reflex in both the efferent and afferent pathways. The pathological findings of Matsuyama and Haymaker (1967) revealed lesions of the intermediolateral horns of the spinal cord, sympathetic trunk, ganglia, and the IXth and Xth cranial nerves.

Although stress may have played a part in the increased urinary VMA excretions in our patients, this could also be due to irritative lesions of the sympathetic nervous system and failure of uptake of catecholamines in damaged parts of this system. It is known that a denervav ted organ has heightened sensitivity to catecholo amines and the cardiovascular disturbance seet in our patients may be due to the combined effect of increased concentrations of catechol? amines and impairment of the carotid sinus reflex. The subarachnoid haemorrhage could have contributed to the high VMA urinary excretion in patient no. 1, though Hallpike, Claveria, Cohen, and Lascelles (1971) report normal values of catecholamine excretion in this condition. Our finding of increased catecholamine excretion in the Guillain-Barré syndrome confirms Mitchell and Meilman's (1967) original observation. Transient non-specific ECG changes were noted in their case and myocarditis was seen in seven cases examined by Haymaker and Kernohan (1949). Van Vliet, Burchell, and Titus (1966) found similar myocardial lesions in patients with phaeochromocytoma and it is possible that the ECG changes in the GuillainBarré syndrome are due to the increased catecholamine levels.

Stress associated with the illness was probably responsible for the increased urinary excretions of 17-OHCS and high plasma cortisol levels with loss of diurnal variation (Jacobs and Nabarro, 1961).

We have been able to find only one previous report, by Kocen (1957), of the association of 
impaired glucose tolerance and the GuillainBarré syndrome. Increased blood levels of catecholamines and cortisol found in our patients probably contributed to this.

The mechanisms responsible for the increased catecholamine excretion in patients with the Guillain-Barré syndrome need further elucidation. Increased concentrations of noradrenaline relative to adrenaline would support the hypothesis that it is due to a sympathetic nervous system disturbance rather than to adrenal medullary stimulation secondary to stress. The administration of $\alpha$-adrenergic and $\beta$-adrenergic blocking drugs to patients with life-threatening cardiovascular disturbance should certainly be considered.

We thank Dr. J. Donald Ball for allowing us to study patients under his care, the Department of Clinical Chemistry, Llandough Hospital, for glucose and VMA estimations, the Tenovus Institute, Cardiff, for steroid estimations, and Dr. J. Henry Jones, consultant physician, Cardiff Royal Infirmary, for criticism of the manuscript.

\section{REFERENCES}

Appenzeller, O., and Marshall, J. (1963). Vasomotor disturbance in Landry-Guillain-Barré syndrome. Archives of Neurology, 9, 368-372.

Clark, A., and Timms, B. G. (1968). Reduced 2,6-dichlorophenol-indiphenol as a replacement for o-tolidine in the enzymatic determination of blood glucose. Clinica Chimica Acta, 20, 352-354.

Eiben, R. M., and Gersony, W. M. (1963). Recognition, prognosis and treatment of the Guillain-Barré syndrome (acute idiopathic polyneuritis). Medical Clinics of North America, 47, 1371-1380.

Few, J. D. (1961). A method for the analysis of urinary 17-hydroxycorticosteroids. Journal of Endocrinology, 22, $31-46$.

Georges, R. J., and Small, N. A. (1962). The determination of 3-methoxy 4-hydroxy mandelic acid in urine. Journal of Clinical Pathology, 15, 388-389.

Hallpike, J. F., Claveria, L. E., Cohen, N. M., and Lascelles, P. T. (1971). Glucose tolerance and plasma insulin levels in subarachnoid haemorrhage. Brain, 94, 151-164.

Haymaker, W., and Kernohan, J. W. (1949). LandryGuillain-Barré syndrome. Clinico-pathologic report of fifty fatal cases and a critique of the literature. Medicine (Baltimore), 28, 59-141.

Jacobs, H. S., and Nabarro, J. D. N. (1969). Plasma 11 hydroxycorticosteroid and growth hormone levels in acute medical illnesses. British Medical Journal, 2, 595-598.

Kocen, R. S. (1957). Diabetes mellitus with acute polyneuritis. British Medical Journal, 2, 100-101.

Marshall, J. (1963). The Landry-Guillain-Barré syndrome. Brain, 86, 55-66.

Matsuyama, H., and Haymaker, W. (1967). Distribution of lesions in the Landry-Guillain-Barré syndrome with emphasis on involvement of the sympathetic system. Acta Neuropathologica, 8, 230-241.

Mattingly, D. (1962). A simple fluorimetric method for the estimation of free 11-hydroxycorticoids in human plasma. Journal of Clinical Pathology, 15, 374-379.

Miller, H. (1966). Polyneuritis. British Medical Journal, 2, 1219-1225.

Mitchell, P. L., and Meilman, E. (1967). The mechanism of hypertension in the Guillain-Barré syndrome. American Journal of Medicine, 42, 986-995.

Spalding, J. M. K., and Smith, A. C. (1963). Clinical Practice and Physiology of Artificial Respiration, p. 100. Blackwell Scientific Publications: Oxford.

Van Vliet, P. D., Burchell, H. B., and Titus, J. L. (1966). Focal myocarditis associated with pheochromocytoma. New England Journal of Medicine, 274, 1102-1108. 